\title{
Intakes and perceived home availability of sugar-sweetened beverages, fruit and vegetables as reported by mothers, fathers and adolescents in the HEIA (HEalth In Adolescents) study
}

\author{
Mona Bjelland ${ }^{1, *}$, Nanna Lien ${ }^{1}$, May Grydeland ${ }^{1,2}$, Ingunn H Bergh ${ }^{3}$, \\ Sigmund A Anderssen ${ }^{2}$, Yngvar Ommundsen ${ }^{3}$, Knut-Inge Klepp ${ }^{1}$ and Lene F Andersen ${ }^{1}$ \\ 'Department of Nutrition, Faculty of Medicine, University of Oslo, PO Box 1046 Blindern, NO-0316 Oslo, \\ Oslo, Norway: ${ }^{2}$ Department of Sports Medicine, Norwegian School of Sport Sciences, Oslo, Norway: \\ ${ }^{3}$ Department of Coaching and Psychology, Norwegian School of Sport Sciences, Oslo, Norway
}

Submitted 18 June 2010: Accepted 22 March 2011: First published online 31 May 2011

\begin{abstract}
Objective: To investigate the intakes of sugar-sweetened beverages (SSB), fruit and vegetables (FV) among adolescents and their parents and to explore differences in the perceived availability by gender and parental education.

Design: Baseline data from the HEIA (HEalth In Adolescents) study.

Setting: Data on intake of SSB were collected assessing frequency and amounts, whereas consumption of FV was assessed on the basis of frequency. Further, perceived availability at home and at school (taken from home) was reported. Subjects: Participants were 1528 Norwegian adolescents aged 11 years, as well as 1200 mothers and 1057 fathers.

Results: The adolescents' intake of SSB was low on weekdays but doubled during weekend days. This pattern was observed among parents as well. There were significant differences in intake between boys, girls, mothers and fathers, except for vegetables. Fathers reported the lowest frequency of FV intake. Compared with adolescents, mothers reported lower availability of SSB and higher availability of FV. Compared with their sons, fathers reported higher availability of vegetables and lower availability of sugar-sweetened fruit drinks at school. Significant differences in adolescents' intake of SSB and in the perceived availability of both SSB and FV by parental education were found.

Conclusions: The intake of SSB was higher during weekend days than during weekdays, whereas the frequency of FV intake was low. Differences in adolescents' perceived availability of both SSB and FV on the basis of parental education were found, whereas the differences in intake were significant only for SSB. Increasing parental awareness of availability and their potential as role models across parental gender and educational level could improve adolescents' dietary habits.
\end{abstract}

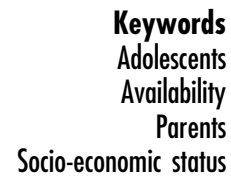

Intervention programmes aiming to improve adolescents' dietary habits and prevent obesity have to a large extent targeted schools, which have the potential to reach all adolescents in stable and established settings ${ }^{(1,2)}$. However, in order to develop effective programmes recent research has emphasized the need to include the home food environment because family and parents have a major influence on adolescents' eating behaviours ${ }^{(3-6)}$. Therefore, it is important to increase knowledge of the parental perception of the home food environment and its association with adolescents' dietary intakes and perceptions, across socio-economic groups ${ }^{(7)}$.

In 2003, the intakes of fruit and vegetables (FV) were far below dietary guidelines (five portions per day) among a nationally representative sample of 11-year-olds in Norway. Only $19.5 \%$ of girls and $13.3 \%$ of boys consumed the recommended number of $\mathrm{FV}$ portions ${ }^{(8)}$. On average, 9- and 13-year-olds had mean added sugar intakes of 80 and $95 \mathrm{~g} / \mathrm{d}$, respectively, in the national Ungkost study conducted in 2000. Soft drinks/sugar-sweetened fruit drinks contributed to $31-53 \%$ of the intake of added sugar ${ }^{(9)}$. Recent reviews on the relationship between sugar-sweetened beverages (SSB) and body weight development reported a positive association between consumption of SSB and body weight ${ }^{(10-13)}$; however, there is a need for more interventional and prospective observational studies investigating this association. More studies exploring the association between FV intake and body weight are needed as well ${ }^{(14,15)}$. 
Studies on determinants of young peoples' eating behaviour in the home environment have mainly been conducted for their FV consumption, and parental intake and home availability/accessibility are some of the most consistently supported determinants ${ }^{(16-18)}$. Despite being recommended, only a limited number of studies have examined associations for boys and girls separately ${ }^{(18)}$ and the inclusion of more data from fathers has been requested $^{(6,19)}$. Six European studies and one US study recently assessed parent-child agreement of intake and/or the determinants of $\mathrm{FV}$ intake ${ }^{(19-25)}$, but only two of them were stratified by gender dyads ${ }^{(24,25)}$. For SSB, the number of studies investigating determinants are more limited; however, the conclusions drawn are that soft drink consumption by parents and availability at home seem to be strong determinants of adolescents' consumption ${ }^{(16,26,27)}$. Only two studies have been found investigating the parent-child agreement of intake and/or determinants of SSB, both stratified by gender dyads ${ }^{(24,25)}$. In addition, the socioeconomic status (e.g. parental education) is associated with the intakes of both $\mathrm{FV}$ and $\mathrm{SSB}^{(16-18,28,29)}$.

The eating patterns of children and adolescents are strongly influenced by environmental characteristics ${ }^{(4,30)}$. Modelling can be defined as the perceived behaviour of others, making parental eating important as part of the adolescents' socio-cultural environment ${ }^{(3,31)}$. Availability/ accessibility of food concerns whether foods of interest are perceived to be present in an environment ${ }^{(32)}$ and whether they are part of the adolescents' physical environment ${ }^{(3,31)}$. The parental educational level is related to diet, nutritional knowledge, food choices and the availability of food and beverages in schools and in the home environment ${ }^{(3,31,33)}$.

The aims of the present paper were: (i) to study the association of intakes of SSB and FV between parents and their adolescent children; (ii) to investigate parent-child agreement on the reporting of perceived availability of SSB and FV at home; and (iii) to assess differences in intake and perceived availability among adolescents whose parents differ in educational level.

\section{Methods}

\section{Study design and subjects}

A total of thirty-seven schools out of the 177 invited schools from the largest towns/municipalities in seven counties surrounding Oslo in Norway agreed to participate in the HEalth In Adolescents (HEIA) study, a schoolbased randomized interventional trial to promote healthy weight among adolescents. All sixth graders of the thirtyseven schools ( $n$ 2165) and their parents/legal guardians (hereafter called parents) were invited to participate. Of them, 1580 (73\%) adolescents returned a parent-signed informed consent form for their participation.

The baseline survey took place over 4 weeks in September 2007. On the day of the survey, the participating adolescents filled an Internet-based questionnaire. The questionnaire comprised mostly pre-coded answer categories and took about $45 \mathrm{~min}$ to complete. Adolescents took home parental questionnaires (paper) and returned them to the teachers in a sealed envelope, which were collected from the schools by project staff. A total of 1528 adolescents (97\% of the 1580 who consented), 1200 mothers (76\%) and 1057 fathers (67\%) completed the baseline questionnaire. Furthermore, $73.6 \%$ of the adolescents reported living with both parents, whereas $13.0 \%$ spent the same amount of time with both parents. Only $1 \cdot 2 \%$ reported living with legal guardians (no parent).

The present study was approved by the Regional Committees for Medical Research Ethics and by the Norwegian Social Science Data Service.

\section{Questionnaires}

Intakes of beverages were assessed by frequency (six categories: from never/seldom to every weekday) and amount (in glasses; four categories: from one glass to four glasses or more) for weekdays and by amount for weekends (in glasses; eight categories: from never/seldom to seven glasses or more). In the questionnaire, the introduction to the question stated that 0.51 of beverage was equal to three glasses, making one glass equal to $1.67 \mathrm{dl}$. Carbonated soft drinks and sugar-sweetened fruit drinks were the main beverages (summed and presented as SSB in $\mathrm{dl} / \mathrm{d}$ ), but carbonated soft drinks and fruit drinks without sugar were also assessed. Frequency of consumption of fruit and raw and cooked vegetables was assessed by one question for each (eight categories: from never/seldom to $\geq 3$ times/d).

Availability of SSB was assessed using two questions about soft drinks with sugar or sugar-sweetened fruit drinks at home and one question about sugar-sweetened fruit drinks at school (brought from home). Similarly, for FV the questionnaire included two questions on availability at home and one question on availability at school (FV brought from home). Availability of vegetables for dinner was assessed through the statement 'At home we usually have vegetables for dinner every day'. Adolescents and parents were asked parallel questions on availability. The variables were dichotomized because of the distribution of data. For SSB at home/in school: never $/$ seldom $=0$, sometimes $/$ most days/always $($ yes $)=$ 1; for $\mathrm{FV}$ at home: never $/$ seldom $/$ sometimes $=0$, most days/always $($ often $)=1$; for vegetables for dinner: completely disagree/disagree a little/neither disagree or agree $=0$, agree a little/completely agree (yes) $=1$; and for FV at school: never/seldom $=0,1-2$ times/week or 3-4 times/week or all days (yes) $=1$. Participants reporting that 'We do not have soft drinks/fruit drinks with sugar at home' have been excluded from the analysis on availability of SSB. Further, those who reported that they took part in the subscription for FV at school were excluded from the analysis of FV taken to school. 
A test-retest study of the questionnaires (on paper) conducted among 114 adolescents, forty-four mothers and thirty-five fathers before the baseline survey indicated that the questions had acceptable to good reliability. Pearson's test-retest correlation coefficients that related to questions on intake ranged from 0.46 to 0.78 for adolescents, from 0.56 to 0.96 for mothers and from 0.69 to 0.94 for fathers. For questions on availability, Pearson's test-retest correlation coefficients were also good $(0 \cdot 56-0 \cdot 84$ for adolescents, $0 \cdot 44-0 \cdot 81$ for mothers and $0 \cdot 42-0 \cdot 82$ for fathers), except for the correlation coefficients for fathers reporting the availability of vegetables at home $(r=0 \cdot 24)$.

Self-reported information about parental education was collected as part of the informed consent form. Education was categorized into three levels on the basis of categories presented by Statistics Norway: $\leq 12$ years (primary, lower secondary and upper secondary education), between 13 and 16 years (higher education up to 4 years' duration) and $>16$ years (higher education $>4$ years' duration) of education. Information about education from the parent with the highest educational level was used in the analyses, or else the one available.

\section{Data analysis}

Clustering effects due to schools being the unit of recruitment were checked using the Linear Mixed Model procedure. There was no clustering effect for the intakes of vegetables, and only $2-3 \%$ of the unexplained variation was on group level for the adolescents' intakes of SSB and fruit. Thus, there was no clustering effect of significance and it was not taken into account in the analyses.

The intakes of SSB and FV are presented as mean and $\mathrm{SD}$, and gender differences were tested using the $t$ test. To assess the association between adolescents' and parental intakes and perceived availability, Pearson's correlation coefficients were computed. Differences in the perceived availability of SSB and FV between adolescents and their mothers and fathers were analysed by cross-tabulation. Statistical significance was evaluated using the McNemar test for detecting differences in responses between the adolescent and parents from the same family. SSB intake variables and the availability data for $\mathrm{FV}$ at home and for sugar-sweetened soft drinks at school showed skewed distribution for adolescents, mothers and fathers; hence, both Pearson's correlation coefficients and Spearman's $\rho$ were computed to assess the association between adolescents and parents. Results from the non-parametric tests were similar to those from parametric tests and the latter were reported because results from parametric tests are easier to interpret, showing real values compared with rank scores. The percentages of adolescents who perceived SSB and FV as being available at home and in school were calculated for the three levels of parental education and tested using the $\chi^{2}$ test. Data were analysed using the IBM Statistical Package for the Social Sciences statistical software package version $16 \cdot 0$ (IBM Corp., New York, NY, USA).

\section{Results}

\section{Intake}

The intakes of SSB among Norwegian 11-year-olds were low during weekdays but nearly doubled on a weekend day. This pattern was also observed for parents. The intakes were significantly different between girls, boys, mothers and fathers both on weekdays and on weekend days. The frequency of intake of fresh fruit also differed significantly between groups. The intakes of raw and cooked vegetables were almost the same for girls, boys and mothers, whereas the fathers reported a significantly lower frequency (Table 1a). The correlations between the adolescents' and parents' intakes were significant at the $0 \cdot 01$ level for SSB, vegetables and fresh fruit (only girls and mothers; Table 1b). The correlations for SSB during weekdays were highest for boys and mothers $(r=0 \cdot 34)$ and lowest for girls and fathers $(r=0 \cdot 13)$. The pattern was the same for a weekend day. The parent-child correlations for the intakes of $\mathrm{FV}$ were significant but $<0 \cdot 20$.

\section{Perceived availability - girls and parents}

Overall, the proportions of parents and adolescents reporting similar levels of perceived availability were high. Significant differences in perceived availability between girls and mothers were found for availability of FV at home, for consumption of vegetables for dinner and

Table 1a Intakes of SSBt and FV by gender in a group of 11-year-old Norwegian adolescents and their parents

\begin{tabular}{|c|c|c|c|c|c|c|c|c|}
\hline \multirow[b]{2}{*}{ Intake } & \multicolumn{2}{|c|}{ Girls (n 703)‡ } & \multicolumn{2}{|c|}{ Boys (n 734) } & \multicolumn{2}{|c|}{ Mothers $(n 1151) \ddagger$} & \multicolumn{2}{|c|}{ Fathers (n 989) $\ddagger$} \\
\hline & Mean & SD & Mean & SD & Mean & SD & Mean & SD \\
\hline Age (years) & $11 \cdot 2$ & $0 \cdot 27$ & $11 \cdot 2$ & $0 \cdot 26$ & $40 \cdot 9$ & $4 \cdot 8$ & $43 \cdot 4$ & $5 \cdot 6$ \\
\hline SSB (dl/weekday) & $1 \cdot 0$ & $1 \cdot 4$ & $1 \cdot 4$ & $1 \cdot 9$ & $0 \cdot 3$ & 0.9 & $0 \cdot 8$ & $1 \cdot 4$ \\
\hline SSB (dl/weekend day) & $2 \cdot 1$ & $1 \cdot 8$ & $2 \cdot 5$ & $2 \cdot 1$ & 0.9 & $1 \cdot 5$ & $1 \cdot 5$ & 1.9 \\
\hline Fresh fruit (times/d) & $1 \cdot 5$ & $1 \cdot 0$ & $1 \cdot 3$ & $1 \cdot 0$ & $1 \cdot 2$ & $0 \cdot 8$ & 0.8 & 0.7 \\
\hline Raw vegetables (times/d) & $1 \cdot 0$ & 0.9 & 0.9 & 0.9 & $0 . \overline{9}$ & 0.7 & 0.6 & 0.5 \\
\hline Cooked vegetables (times/d) & 0.6 & 0.6 & 0.6 & 0.6 & 0.6 & $0 \cdot 3$ & 0.5 & $0 \cdot 4$ \\
\hline
\end{tabular}

SSB, sugar-sweetened beverages; FV, fruit and vegetables.

tSoft drinks with sugar and sugar-sweetened fruit drinks.

¥The numbers vary slightly across food items. 
Table 1b The correlations between the child's, mother's and father's intakes of SSBt and FV in a group of 11-year-old Norwegian adolescents and their parents

\begin{tabular}{|c|c|c|c|c|}
\hline \multirow[b]{2}{*}{ Intake } & \multicolumn{4}{|c|}{ Correlations } \\
\hline & Girl-mother ( $n$ 573)‡ & Boy-mother $(n$ 541) $\ddagger$ & Girl-father ( $n$ 485)‡ & Boy-father $(n 480) \ddagger$ \\
\hline SSB (dl/weekday) & $0 \cdot 19^{\star \star}$ & $0 \cdot 34^{\star \star}$ & $0 \cdot 13^{\star \star}$ & $0 \cdot 22^{\star \star}$ \\
\hline SSB (dl/weekend day) & $0 \cdot 20^{\star \star}$ & $0 \cdot 26^{\star \star}$ & $0 \cdot 17^{\star \star}$ & $0 \cdot 24^{\star \star}$ \\
\hline Fresh fruit (times/d) & $0 \cdot 14^{\star *}$ & 0.06 & 0.08 & $0 \cdot 09^{*}$ \\
\hline Raw vegetables (times/d) & $0 \cdot 09^{*}$ & $0 \cdot 19^{\star *}$ & $0 \cdot 13^{\star \star}$ & $0 \cdot 12^{\star \star}$ \\
\hline Cooked vegetables (times/d) & $0 \cdot 17^{\star \star}$ & $0 \cdot 14^{\star \star}$ & $0 \cdot 14^{\star *}$ & $0 \cdot 11^{*}$ \\
\hline
\end{tabular}

SSB, sugar-sweetened beverages; FV, fruit and vegetables.

Pearson's correlation is significant at ${ }^{*} 0.05$ and ${ }^{* *} 0.01$ levels.

tSoft drinks with sugar and sugar-sweetened fruit drinks.

$\ddagger$ The numbers vary slightly across food items.

for sugar-sweetened fruit drinks taken to school (Table 2). For $8 \%$ of the daughter-mother pairs, the mothers reported fruit to be available at home, whereas the daughters reported seldom/never available. Similarly, $14 \%$ of mothers perceived vegetables to be available at home compared with the daughters who perceived it as seldom/never available. Approximately $26 \%$ of mothers agreed that vegetables were available for dinner, whereas the daughters disagreed. Finally, $8 \%$ of mothers reported that their daughter never/seldom took sugar-sweetened fruit drinks to school, whereas the daughter reported positively on taking them to school. No significant differences were found in perceived availability between daughters and fathers.

\section{Perceived availability - boys and parents}

For boys, significant differences were found for soft drinks with sugar and for availability of vegetables at home, vegetables for dinner and for sugar-sweetened fruit drinks taken to school (Table 3). In total 19\% of the boys reported soft drinks with sugar to be available at home, whereas the mothers reported seldom/never available. Further, $15 \%$ of mothers perceived vegetables to be available at home compared with the sons who found them seldom/never available. Approximately 29\% of mothers agreed that vegetables were available for dinner, whereas the sons disagreed. Finally, $11 \%$ of mothers reported that their son never/seldom took sugarsweetened fruit drinks to school, whereas the sons reported positively on taking them to school. The same patterns were found for fathers and sons; significant differences were detected for availability of vegetables at home, vegetables for dinner and for sugar-sweetened fruit drinks taken to school. As for mothers and sons, $15 \%$ of fathers perceived vegetables to be available at home compared with the sons finding them seldom/ never available. Approximately $26 \%$ of fathers agreed that vegetables were available for dinner, whereas the sons disagreed. Finally, 10\% of fathers reported that their son never/seldom took sugar-sweetened fruit drinks to school, whereas the sons reported positively on taking them to school.

\section{Associations between parents' and their adolescent child's perceived availability}

All correlations between adolescents' and parents' perceived availability were significant at $P \leq 0 \cdot 01$. Pearson's correlation coefficients were overall $0 \cdot 3 \quad(0 \cdot 24-0 \cdot 40)$ for SSB (at home and in school), $0 \cdot 2(0 \cdot 12-0 \cdot 26)$ for FV at home and $0.6(0.61-0.70)$ for $\mathrm{FV}$ in school (data not shown).

\section{Parental education - intake and availability}

For both girls and boys there was a significant negative association between intakes of SSB $(P \leq 0 \cdot 001)$ and parental educational level (Table 4). No significant difference in intakes of FV on the basis of parental education was found. Significant differences in the perceived availability of SSB (at home and in school) by parental education were found for both girls and boys: the higher the parental education the lower the proportion of adolescents reporting SSB to be available (Table 5). The proportion of adolescents reporting fruit available at home, vegetables served for dinner and FV taken to school was significantly higher among adolescents having parents with higher levels of education. For girls there were significant differences in the perceived availability of vegetables at home, whereas no significant differences were found among boys when stratified by parental education.

\section{Discussion}

The intakes of SSB among Norwegian 11-year-olds and their parents were higher during weekend days compared with weekdays, whereas the frequencies of $\mathrm{FV}$ intake were low. Mothers reported a lower availability of SSB and a higher availability of FV compared with adolescents, whereas fathers perceived the availability of vegetables to be higher and the availability of sugarsweetened fruit drinks taken to school to be lower, compared with their sons. Finally, significant differences in adolescents' perceived availability of both SSB and FV by parental education were found, whereas the differences in intake were significant only for SSB. 
Table 2 Percentages of parent-daughter pairs according to the perceived availability reported for SSBt and FV

Pairs

Pairs

\begin{tabular}{|c|c|c|c|c|c|c|c|c|c|c|c|}
\hline & $\mathrm{D}-\mathrm{M}-$ & $\mathrm{D}+\mathrm{M}-$ & $\mathrm{D}-\mathrm{M}+$ & $\mathrm{D}+\mathrm{M}+$ & & & $\mathrm{D}-\mathrm{F}-$ & $\mathrm{D}+\mathrm{F}-$ & $\mathrm{D}-\mathrm{F}+$ & $\mathrm{D}+\mathrm{F}+$ & \\
\hline$n$ & $\%$ & $\%$ & $\%$ & $\%$ & $P \ddagger$ & $n$ & $\%$ & $\%$ & $\%$ & $\%$ & $P \ddagger$ \\
\hline 445 & $60 \cdot 7$ & $15 \cdot 3$ & $11 \cdot 7$ & $12 \cdot 4$ & $0 \cdot 171$ & 396 & $58 \cdot 1$ & $12 \cdot 4$ & $17 \cdot 7$ & 11.9 & 0.066 \\
\hline 432 & $29 \cdot 2$ & $18 \cdot 8$ & $17 \cdot 8$ & $34 \cdot 3$ & 0.811 & 381 & $27 \cdot 3$ & $16 \cdot 8$ & 18.9 & $37 \cdot 0$ & 0.549 \\
\hline 598 & $1 \cdot 7$ & $4 \cdot 3$ & $7 \cdot 9$ & $86 \cdot 1$ & $0.019^{\star}$ & 509 & $2 \cdot 0$ & $6 \cdot 3$ & $8 \cdot 1$ & $83 \cdot 7$ & 0.349 \\
\hline 596 & 3.5 & 6 . & $14 \cdot 3$ & $75 \cdot 8$ & $<0.001$ & 517 & $5 \cdot 6$ & $11 \cdot 2$ & $12 \cdot 4$ & $70 \cdot 8$ & 0.651 \\
\hline 595 & $7 \cdot 6$ & $9 \cdot 2$ & $25 \cdot 7$ & $57 \cdot 5$ & $<0.001^{\star \star \star}$ & 510 & $11 \cdot 4$ & $17 \cdot 6$ & $21 \cdot 8$ & $49 \cdot 2$ & $0 \cdot 158$ \\
\hline 595 & 84.5 & $7 \cdot 9$ & $3 \cdot 2$ & $4 \cdot 4$ & $0 \cdot 001^{\star \star \star}$ & 513 & $82 \cdot 3$ & $8 \cdot 4$ & $6 \cdot 2$ & $3 \cdot 1$ & 0.248 \\
\hline 488 & $12 \cdot 3$ & $7 \cdot 8$ & $22 \cdot 5$ & $77 \cdot 5$ & $0 \cdot 241$ & 390 & 14.9 & $11 \cdot 0$ & 7.9 & $66 \cdot 2$ & 0.201 \\
\hline
\end{tabular}

Availability at home

When soft drinks with sugar are available at home, can you (your child) serve yourself

(herself) as you (she) please(s)?

When sugar-sweetened fruit drinks are available at home, can you (your child) serve

yourself (herself) as you (she) please(s)? ?

How often is fruit that you (your child) like(s) available at home?§

How otten are there vegetables that you (your child) like(s) available at home?

At home we usually have vegetables for dinner every day

Availability at school (taken from home)

lake sugar-sweetened fruit drinks to school?

does your child take fruit or vegetables to school?§॥

SSB, sugar-sweetened beverages; FV, fruit and vegetables; D-M-, both daughter and mother reported not available; D+M-, daughter reported available, mother reported not available; D-M +, daughter reported no available, mother reported available; $\mathrm{D}+\mathrm{M}+$, both daughter and mother reported available; $\mathrm{D}-\mathrm{F}-$, both daughter and father reported not available; $\mathrm{D}+\mathrm{F}-$, daughter reported available, father reported not available; $\mathrm{D}-\mathrm{F}+$, daughter reported not available, father reported available; $\mathrm{D}+\mathrm{F}+$, both daughter and father reported available.

Significant at ${ }^{*} 0.05$ and ${ }^{* *} 0.001$ levels.

Soft drinks with sugar and sugar-sweetened fruit drinks.

$¥$ McNemar test.

作 , a

IPairs participating in the fruit subscription programme according to mothers were excluded ( $19 \cdot 5 \%$ of the total sample).

Table 3 Percentages of parent-son pairs according to the perceived availability reported for SSBt and FV

Table 3 Percentages of parentson pais accoding to the perived avalabily repoted for sSBt and

Pairs Pairs

\begin{tabular}{|c|c|c|c|c|c|c|c|c|c|c|c|}
\hline & $\mathrm{S}-\mathrm{M}-$ & $\mathrm{S}+\mathrm{M}-$ & $\mathrm{S}-\mathrm{M}+$ & $\mathrm{S}+\mathrm{M}+$ & & & $\mathrm{S}-\mathrm{F}-$ & $\mathrm{S}+\mathrm{F}-$ & $\mathrm{S}-\mathrm{F}+$ & $\mathrm{S}+\mathrm{F}+$ & \\
\hline$n$ & $\%$ & $\%$ & $\%$ & $\%$ & $P \neq$ & $n$ & $\%$ & $\%$ & $\%$ & $\%$ & $P \ddagger$ \\
\hline 435 & 57.9 & $19 \cdot 1$ & $11 \cdot 7$ & $11 \cdot 3$ & $0.007^{\star *}$ & 403 & $53 \cdot 8$ & $18 \cdot 1$ & $15 \cdot 4$ & $12 \cdot 7$ & 0.390 \\
\hline 415 & $28 \cdot 0$ & $20 \cdot 2$ & $15 \cdot 4$ & $36 \cdot 4$ & 0.118 & 381 & $27 \cdot 3$ & $16 \cdot 8$ & 18.9 & $37 \cdot 0$ & 0.549 \\
\hline 578 & 1. & 6 . & $8 \cdot 7$ & $83 \cdot 0$ & $0 \cdot 1$ & 517 & $2 \cdot 7$ & $7 \cdot 7$ & $7 \cdot 9$ & 81 & $1 \cdot 000$ \\
\hline 580 & 6 & 6. & $14 \cdot 8$ & $72 \cdot 6$ & $<0.001^{\star \star \star}$ & 515 & $6 \cdot 8$ & 8.5 & $14 \cdot 8$ & $69 \cdot 9$ & $0.004^{\star \star}$ \\
\hline 576 & $11 \cdot 6$ & $8 \cdot 7$ & $29 \cdot 2$ & 50.5 & $<0.001^{\star \star \star}$ & 510 & $11 \cdot 6$ & $12 \cdot 4$ & $26 \cdot 1$ & $50 \cdot 0$ & $<0.001^{\star \star}$ \\
\hline 574 & $82 \cdot 4$ & $10 \cdot 8$ & $2 \cdot 8$ & $4 \cdot 0$ & $<0 \cdot 001^{\star * *}$ & 521 & $82 \cdot 3$ & $10 \cdot 0$ & 3.8 & 3.8 & $<0.001^{\star \star}$ \\
\hline 440 & $25 \cdot 0$ & $8 \cdot 6$ & $11 \cdot 8$ & 54.5 & $0 \cdot 170$ & 361 & $26 \cdot 9$ & $9 \cdot 7$ & $10 \cdot 2$ & $53 \cdot 2$ & 0.906 \\
\hline
\end{tabular}

Availability at home

When soft drinks with sugar are available at home, can you (your child) serve yourself

(himself) as you (he) please(s)?

When sugar-sweetened fruit drinks are available at home, can you (your child) serve

yourself (himself) as you (he) please(s)?

How often is fruit that you (your child) like(s) available at home?§

How often are there vegetables that you (your child) like(s) available at home?

At home we usually have vegetables for dinner every day

Availability at school (taken from home)

Do(es) you (your child) usually take sugar-sweetened fruit drinks to school?

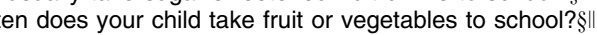

SSB, sugar-sweetened beverages; FV, fruit and vegetables; S-M-, both son and mother reported not available; S+M-, son reported available, mother reported not available; S-M+, son reported not available, mother reported available; $\mathrm{S}+\mathrm{M}+$, both son and mother reported available; $\mathrm{S}-\mathrm{F}-$, both son and father reported not available; $\mathrm{S}+\mathrm{F}-$, son reported available, father reported not available; $\mathrm{S}-\mathrm{F}+$, son reported not available, father reported available; $\mathrm{S}+\mathrm{F}+$, both son and father reported available.

Significant at 0.01 and 0.001 levels.

Soft drinks with sugar and sugar-sweetened fruit drinks.

\$SSB at home/in school: never/seldom $=0$, sometimes/most days/always $=1 ; \mathrm{FV}$ at home: never/seldom/sometimes $=0$, most days/always $=1 ;$ vegetables for dinner: completely disagree/disagree a little/neither 作

Pairs participating in the fruit subscription programme according to mothers were excluded (19.5\% of the total sample). 
Table 4 Intakes of SSBt and FV on the basis of parental education in a group of 11-year-old Norwegian adolescents

\begin{tabular}{|c|c|c|c|c|c|c|c|}
\hline \multirow[b]{2}{*}{ Intake } & \multicolumn{2}{|c|}{$\leq 12$ years } & \multicolumn{2}{|c|}{$13-16$ years } & \multicolumn{2}{|c|}{$>16$ years } & \multirow[b]{2}{*}{$P \neq$} \\
\hline & Mean & SD & Mean & SD & Mean & SD & \\
\hline Girls & \multicolumn{2}{|c|}{$(n 211) \S$} & \multicolumn{2}{|c|}{$(n 228) \S$} & \multicolumn{2}{|c|}{$(n 243) \S$} & \\
\hline SSB (dl/weekday) & $1 \cdot 4$ & $1 \cdot 8$ & $1 \cdot 0$ & $1 \cdot 4$ & $0 \cdot 7$ & $1 \cdot 0$ & $<0.001^{\star \star *}$ \\
\hline SSB (dl/weekend day) & $2 \cdot 4$ & $2 \cdot 0$ & $2 \cdot 2$ & $1 \cdot 7$ & $1 \cdot 8$ & $1 \cdot 6$ & $0.001^{\star * \star}$ \\
\hline Fresh fruit (times/d) & 1.5 & $1 \cdot 0$ & $1 \cdot 5$ & $1 \cdot 0$ & $1 \cdot 6$ & $1 \cdot 0$ & 0.448 \\
\hline Raw vegetables (times/d) & $1 \cdot 0$ & $0 \cdot 9$ & $1 \cdot 0$ & 0.9 & $1 \cdot 1$ & $0 \cdot 9$ & 0.396 \\
\hline Cooked vegetables (times/d) & $0 \cdot 7$ & $0 \cdot 7$ & $0 \cdot 6$ & 0.6 & $0 \cdot 7$ & $0 \cdot 6$ & $0 \cdot 367$ \\
\hline \multicolumn{3}{|c|}{$(n 200) \S$} & \multicolumn{2}{|c|}{$(n 277) \S$} & \multicolumn{2}{|c|}{$(n 226) \S$} & \\
\hline SSB (dl/weekday) & $1 \cdot 8$ & $2 \cdot 2$ & $1 \cdot 4$ & $1 \cdot 9$ & $1 \cdot 1$ & $1 \cdot 4$ & $<0.001^{* * *}$ \\
\hline SSB (dl/weekend day) & $2 \cdot 9$ & $2 \cdot 5$ & $2 \cdot 4$ & $2 \cdot 0$ & $2 \cdot 2$ & $1 \cdot 8$ & $0.001^{\star \star \star}$ \\
\hline Fresh fruit (times/d) & $1 \cdot 3$ & $1 \cdot 0$ & $1 \cdot 4$ & $1 \cdot 0$ & $1 \cdot 3$ & 0.9 & 0.435 \\
\hline Raw vegetables (times/d) & $1 \cdot 0$ & $1 \cdot 0$ & $1 \cdot 0$ & 0.9 & 0.9 & $0 \cdot 8$ & 0.588 \\
\hline Cooked vegetables (times/d) & $0 \cdot 6$ & $0 \cdot 8$ & 0.5 & $0 \cdot 6$ & 0.5 & 0.5 & $0 \cdot 286$ \\
\hline
\end{tabular}

SSB, sugar-sweetened beverages; FV, fruit and vegetables.

Significant at ${ }^{* \star *} 0.001$ level.

†Soft drinks with sugar and sugar-sweetened fruit drinks.

$\ddagger$ One-way ANOVA.

$\S$ The numbers vary slightly across food items.

Table 5 Availability of SSBt and FV on the basis of parental education in a group of 11-year-old Norwegian adolescents

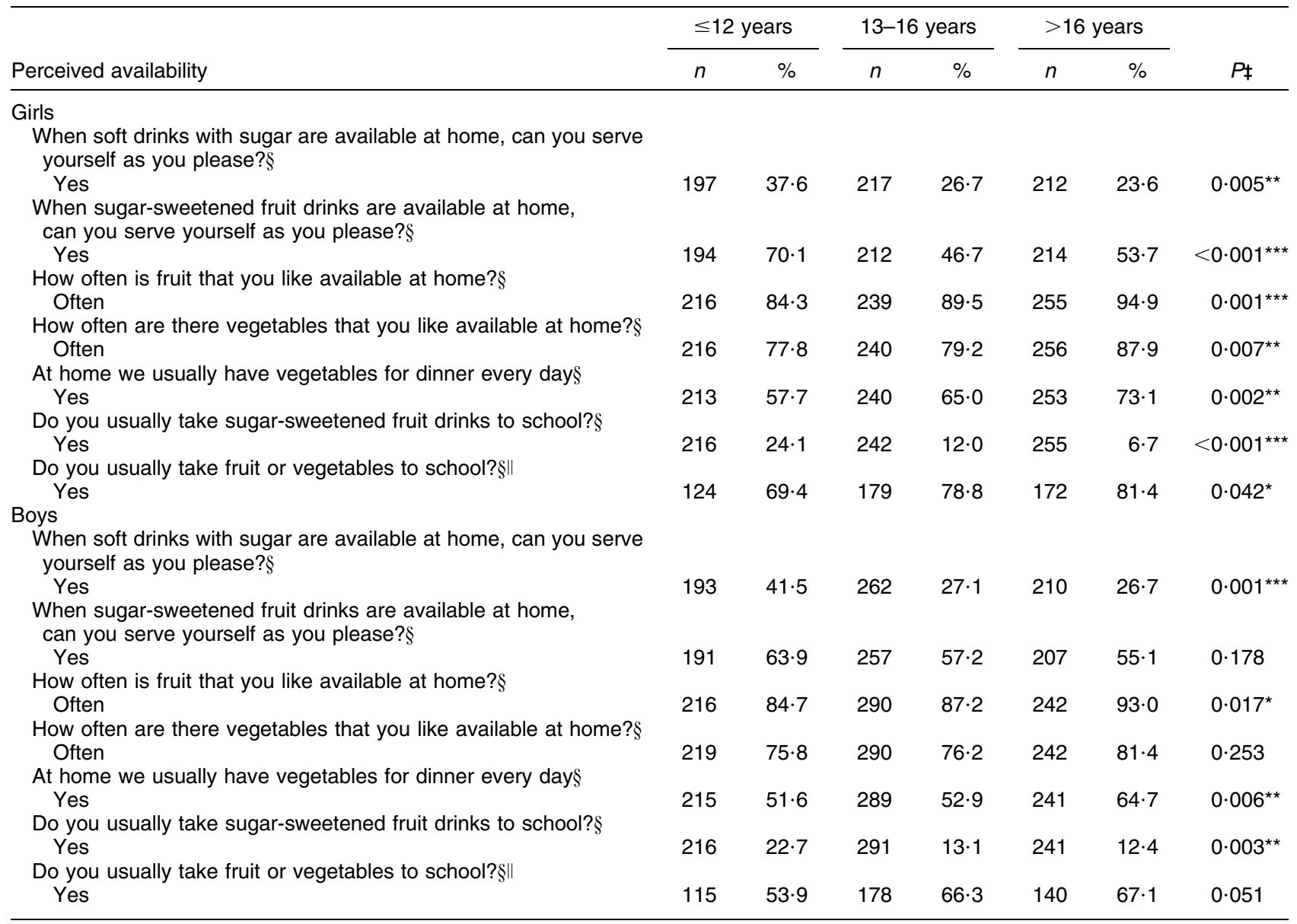

SSB, sugar-sweetened beverages; FV, fruit and vegetables.

$\neq$ The $x^{2}$ test. Significant at ${ }^{\star} 0.05$, ${ }^{\star *} 0.01$ and ${ }^{\star *} 0.001$ levels.

tSoft drinks with sugar and sugar-sweetened fruit drinks.

$\S S S B$ at home/in school: yes = sometimes/most days/always; FV at home: often = most days/always; vegetables for dinner: yes =agree a little/completely agree; FV at school: yes $=1-2$ times/week or 3-4 times/week or all days.

\|Participants in the fruit subscription programme were excluded (19.5\% of the total participants). 


\section{Associations between parents' and their adolescent child's intakes}

The correlations between adolescents' and parents' intakes of SSB and FV were relatively weak. In a study including 1441 Swedish families (mother, father and child), Elfhag et $a l^{(24)}$ found that the parent-child correlations for intakes of fruit, vegetables and soft drinks were higher than those observed in our study. Beydoun and Wang ${ }^{(25)}$ found that the parent-child correlations between 2-18-year-old children and their mothers and fathers from 1473 households were higher for the combined intakes of FV $(\mathrm{g} / \mathrm{d})$. The correlations of total soft drinks $(\mathrm{g} / \mathrm{d})$ were closer to the coefficients in our study. There are several possible methodological explanations for the observed differences in correlations. The measure of intake differed with respect to both the manner in which frequency was reported and the way in which groups of food and beverages were combined. Differences also existed with regard to the age of the children, the response rates among parents and their representativeness.

\section{Modelling - parental intakes of fruit and vegetables}

Parental eating is one important component of the sociocultural environment of adolescents ${ }^{(3,31)}$. Overall, the frequency of FV intake was low for both mothers and fathers in our study; however, fathers reported a significantly lower frequency of vegetable intake compared with girls, boys and mothers. Elfhag et al. ${ }^{(24)}$ concluded that the most important factor for 12-year-olds' intakes of healthy and unhealthy food and beverages was their parental intakes. Further, in an Icelandic study of 11-yearolds and their parents (90\% mothers), Kristjansdottir et $a{ }^{(19)}$ found that the strongest modelling determinant for fruit was the fathers' fruit intakes (reported by mothers). This is supported by reviews of the literature showing that parental FV intake is positively associated with children's intakes ${ }^{(16-18)}$. This indicates that parents, and in particular fathers, should be made aware of their potential to improve as role models by increasing the frequency of FV intake. However, low correlations between adolescents' and parents' intakes indicate that modelling, in combination with other parenting practices (i.e. encouragement), may be needed to increase the intakes of FV among adolescents ${ }^{(19)}$.

\section{Perceived availability - motbers and adolescents}

Perceptions of dietary components in the adolescents' physical environment may differ between parents and their adolescent children ${ }^{(3,22,31)}$. One variable that may have affected reporting in the present study is the social desirability bias. Our results are in accordance with other studies indicating that social desirability may have caused overestimations in reporting the availability of FV and underestimations in reporting the availability of SSB among mothers. De Bourdeaudhuij and van Oost ${ }^{(34)}$ found that parents (mainly mothers from 104 two-parent families) had higher social desirability compared with children (mean age 15 years) because they wanted to show good parenting. This pattern in response between parents and children has been reported in several other studies as well $^{(20,22,23)}$. An alternative or additional explanation for the difference in perceived availability between adolescents and mothers could be the possibility that the reporting of mothers is more valid. The primary shopper and the preparer of food have considerable influence on the eating pattern of and availability of food for others in the household, particularly children ${ }^{(6,30)}$. Mothers are still the primary caregivers of adolescents in Norway, taking care of home food management practices, and mothers might have a better overview of the FV available at home and the type of fruit drinks (with or without sugar) taken to school. A study by Fischer et al. ${ }^{(35)}$ indicated that mothers' preference may dictate the availability of beverages (milk and SSB); thus, if the mother prefers certain types of beverages without sugar these could be the beverages bought and available.

Finally, it is possible that the adolescents' measures are the most valid; however, in the absence of more objective measures no conclusions can be drawn ${ }^{(22)}$.

\section{Perceived availability - fatbers and adolescents}

The reason why the fathers' perceived availability differs from that of their sons could be that the fathers do not know in detail what is available, taken to school or what kind of vegetables their sons like. No significant differences were found between the perceived availability reported by daughters and fathers. Studies have shown that girls disclose more than boys, indicating that girls communicate better with their parents than do boys ${ }^{(36)}$. This may include their likes and dislikes related to vegetables, which could explain why fathers know more about what kind of vegetables their daughters like. Finally, adolescents might define terms used in the answer categories for availability of items (seldom/sometimes/most days) differently when compared with their parents. Among the sets of correlations, the one between adolescents' and parents' report of FV taken to school was the highest, which may indicate that categories like 1-2 times/week and 3-4 times/week work better, leaving little room for interpretation.

\section{Perceived availability - vegetables}

Kristjansdottir et $a l{ }^{(19)}$ found that the strongest modelling determinant for intake of vegetables was eating vegetables together with the family. In Norway, cooked vegetables are eaten mostly as part of dinner. The adolescents in our study reported a lower availability of cooked vegetables compared with their parents, indicating that the availability of vegetables when eating together with the family was perceived differently. Availability is associated with 
preference $^{(37)}$ and, as hypothesized by Vejrup et al. ${ }^{(38)}$, it might be that, whereas parents perceive vegetables as available when served for dinner, adolescents perceive vegetables to be available only if they like the vegetables served and/or if they perceive the preparation method used as attractive. Another reason for the difference in perceived availability could be that adolescents eat dinner outside their home, in places with a lower availability of cooked vegetables ${ }^{(39)}$. The perceived availability of vegetables at home differed between adolescents and parents. It could be that unless parents make vegetables accessible (in a form and location and at a time that make consumption easy) adolescents may be unaware of its availability at home ${ }^{(32)}$.

\section{Parental education and intakes}

In addition to parental intakes, the educational level of parents constitutes the most important environmental determinant of dietary intakes among children and adolescents ${ }^{(16,18)}$. In our sample of adolescents no significant difference in intakes of FV (times/d) by parental education was detected, which is in accordance with another large Norwegian study ${ }^{(40)}$. This is not in accordance with two other Scandinavian studies in which adolescents of mothers with higher education reported consuming FV more often than did adolescents of mothers with lower education $^{(41,42)}$. MacFarlane et al. ${ }^{(7)}$ found that adolescents of highly educated mothers were more likely to report that vegetables were always served at dinner, concluding that maternal education was linked to home food availability. This could indicate that results are dependent on the educational level of the household reported, on the overall level of education within the family, or mainly on the education of the mothers. The differences in adolescents' intake of SSB on the basis of parental educational level were significant for both girls and boys. These results are in accordance with three other studies reporting that parental educational/occupational level is inversely related to soft drink consumption ${ }^{(28,29,41)}$.

\section{Parental education and perceived availability}

Our results are in accordance with other studies reporting that the higher the parental education the higher the availability of healthy food (FV) and lower the availability of unhealthy food (SSB). A study by Bere et al. ${ }^{(42)}$ indicated that one main reason why adolescents with less-educated parents (mainly maternal education level) consume less FV compared with those with higher parental education is that they have less access to $\mathrm{FV}$ at home. MacFarlane et al. ${ }^{(7)}$ reported that adolescents of high socio-economic position (defined by maternal education) were more likely to report that fruits were always or usually available at home. The availability of vegetables did not vary by socio-economic position, despite the fact that adolescents whose mothers were more highly educated were more likely to report that vegetables were always served for dinner ${ }^{(7)}$. Further,
MacFarlane et al. found a higher proportion of adolescents with less-educated mothers who reported that soft drinks were always or usually available at home ${ }^{(7)}$. These results are in line with studies of food purchasing that reported a significant association between education and food purchasing behaviour. Food shoppers with low levels of education were the least likely to buy and consume healthy food $^{(43,44)}$.

\section{Strengths and limitations}

One of the strengths of the present study is the large sample with a high participation rate of adolescents, mothers and fathers. Another strength is that parental education was reported by the parents themselves and we were able to collect these data from nearly all parents who gave their adolescents consent to participate in the study and not only from those parents answering the questionnaire. Further, parallel questions were asked and the labels on the response scales were similar for adolescents and parents. One of the limitations is that each of the determinants consisted of only one item measure. For FV, only frequencies were collected; no amount or portion sizes were included. The adolescents and parents included in the present study were from the eastern part of Norway; however, as Norway is a rather homogeneous country, the findings may be generalizable to the rest of the population.

\section{Conclusion}

We found that fathers reported a significantly lower frequency of vegetable intakes compared with girls, boys and mothers. Mothers perceived the home availability of SSB to be lower and the availability of FV to be higher compared with adolescents, whereas fathers perceived the availability of vegetables to be higher and the availability of sugar-sweetened fruit drinks taken to school to be lower compared with their sons. There were differences in the perceived availability of both SSB and FV by parental education, whereas the differences in intake were only significant for SSB. These findings may contribute to the development of more effective strategies to transform availability into improvement in the dietary habits of adolescents by making parents and adolescents define and discuss the availability of food and beverages, in particular in families where parents have a low educational level. Furthermore, parents, particularly fathers, should be made aware of their potential to improve as role models by increasing the frequency of FV intake. Future interventions should study the combination of modelling with other parenting practices (i.e. encouragement).

\section{Acknowledgements}

The HEalth In Adolescents study was funded by the Norwegian Research Council (Grant no. 155323/V50) 
with supplementary funds from the Throne Holst Nutrition Research Foundation, University of Oslo, and also from the Norwegian School of Sport Sciences. The authors have no conflict of interest to declare. M.B. worked on the statistical analysis, wrote the first draft of the manuscript and made the greatest contribution to the paper; N.L. was the project coordinator and participated in all aspects of the work. All authors are responsible for the present research and participated in designing the study and in project planning. They provided critical revision of the paper and read and approved the final manuscript. The authors thank all participants and project staff.

\section{References}

1. Brown T \& Summerbell C (2009) Systematic review of school-based interventions that focus on changing dietary intake and physical activity levels to prevent childhood obesity: an update to the obesity guidance produced by the National Institute for Health and Clinical Excellence. Obes Rev 10, 110-141.

2. Van Cauwenberghe E, Maes L, Spittaels H et al. (2010) Effectiveness of school-based interventions in Europe to promote healthy nutrition in children and adolescents: systematic review of published and 'grey' literature. $\mathrm{Br} J$ Nutr 103, 781-797.

3. Rosenkranz RR \& Dzewaltowski DA (2008) Model of the home food environment pertaining to childhood obesity. Nutr Rev 66, 123-140.

4. Story M, Neumark-Sztainer D \& French S (2002) Individual and environmental influences on adolescent eating behaviors. J Am Diet Assoc 102, Suppl. 3, S40-S51.

5. Scaglioni S, Salvioni M \& Galimberti C (2008) Influence of parental attitudes in the development of children eating behaviour. Br J Nutr 99, Suppl. 1, S22-S25.

6. Hanson NI, Neumark-Sztainer D, Eisenberg ME et al. (2005) Associations between parental report of the home food environment and adolescent intakes of fruits, vegetables and dairy foods. Public Health Nutr 8, 77-85.

7. MacFarlane A, Crawford D, Ball K et al. (2007) Adolescent home food environments and socioeconomic position. Asia Pac J Clin Nutr 16, 748-756.

8. Yngve A, Wolf A, Poortvliet E et al. (2005) Fruit and vegetable intake in a sample of 11-year-old children in 9 European countries: The Pro Children Cross-sectional Survey. Ann Nutr Metab 49, 236-245.

9. Overby NC, Lillegaard IT, Johansson L et al. (2004) High intake of added sugar among Norwegian children and adolescents. Public Health Nutr 7, 285-293.

10. Harrington $S$ (2008) The role of sugar-sweetened beverage consumption in adolescent obesity: a review of the literature. J Sch Nurs 24, 3-12.

11. Wolff E \& Dansinger ML (2008) Soft drinks and weight gain: how strong is the link? Medscape J Med 10, 189.

12. Gibson S (2008) Sugar-sweetened soft drinks and obesity: a systematic review of the evidence from observational studies and interventions. Nutr Res Rev 21, 134-147.

13. Libuda L \& Kersting M (2009) Soft drinks and body weight development in childhood: is there a relationship? Curr Opin Clin Nutr Metab Care 12, 596-600.

14. Newby PK (2009) Plant foods and plant-based diets: protective against childhood obesity? Am J Clin Nutr 89, Suppl. 1, S1572-S1587.

15. Alinia S, Hels O \& Tetens I (2009) The potential association between fruit intake and body weight - a review. Obes Rev 10, 639-647.
16. Van Der Horst K, Oenema A, Ferreira I et al. (2007) A systematic review of environmental correlates of obesityrelated dietary behaviors in youth. Health Educ Res 22, 203-226.

17. Rasmussen M, Krolner R, Klepp KI et al. (2006) Determinants of fruit and vegetable consumption among children and adolescents: a review of the literature. Part I: Quantitative studies. Int J Behav Nutr Phys Act 3, 22.

18. Pearson N, Biddle SJ \& Gorely T (2009) Family correlates of fruit and vegetable consumption in children and adolescents: a systematic review. Public Health Nutr 12, 267-283.

19. Kristjansdottir AG, De Bourdeaudhuij I, Klepp KI et al. (2009) Children's and parents' perceptions of the determinants of children's fruit and vegetable intake in a lowintake population. Public Health Nutr 12, 1224-1233.

20. Bere E \& Klepp KI (2004) Correlates of fruit and vegetable intake among Norwegian schoolchildren: parental and selfreports. Public Health Nutr 7, 991-998.

21. Tak NI, Te Velde SJ, de Vries JH et al. (2006) Parent and child reports of fruit and vegetable intakes and related family environmental factors show low levels of agreement. J Hum Nutr Diet 19, 275-285.

22. Reinaerts E, De Nooijer J \& De Vries NK (2007) Parental versus child reporting of fruit and vegetable consumption. Int J Behav Nutr Phys Act 4, 33.

23. Van Assema P, Glanz K, Martens M et al. (2007) Differences between parents' and adolescents' perceptions of family food rules and availability. J Nutr Educ Behav 39, 84-89.

24. Elfhag K, Tholin S \& Rasmussen F (2008) Consumption of fruit, vegetables, sweets and soft drinks are associated with psychological dimensions of eating behaviour in parents and their 12-year-old children. Public Health Nutr 11, 914-923.

25. Beydoun MA \& Wang Y (2009) Parent-child dietary intake resemblance in the United States: evidence from a large representative survey. Soc Sci Med 68, 2137-2144.

26. Grimm GC, Harnack L \& Story M (2004) Factors associated with soft drink consumption in school-aged children. $J \mathrm{Am}$ Diet Assoc 104, 1244-1249.

27. Bere E, Glomnes ES, Te Velde SJ et al. (2008) Determinants of adolescents' soft drink consumption. Public Health Nutr 11, 49-56.

28. Cullen KW, Ash DM, Warneke C et al. (2002) Intake of soft drinks, fruit-flavored beverages, and fruits and vegetables by children in grades 4 through 6. Am J Public Health 92, 1475-1478.

29. Vereecken CA, Inchley J, Subramanian SV et al. (2005) The relative influence of individual and contextual socioeconomic status on consumption of fruit and soft drinks among adolescents in Europe. Eur J Public Health 15, 224-232.

30. Glanz K, Sallis JF, Saelens BE et al. (2005) Healthy nutrition environments: concepts and measures. Am J Health Promot 19, 330-333.

31. Swinburn B, Egger G \& Raza F (1999) Dissecting obesogenic environments: the development and application of a framework for identifying and prioritizing environmental interventions for obesity. Prev Med 29, 563-570.

32. Cullen KW, Baranowski T, Owens E et al. (2003) Availability, accessibility, and preferences for fruit, $100 \%$ fruit juice, and vegetables influence children's dietary behavior. Health Educ Behav 30, 615-626.

33. Hanson MD \& Chen E (2007) Socioeconomic status and health behaviors in adolescence: a review of the literature. J Behav Med 30, 263-285.

34. De Bourdeaudhuij I \& van Oost P (2000) Personal and family determinants of dietary behaviour in adolescents and their parents. Psychol Health 15, 751-770. 
35. Fisher JO, Mitchell DC, Smiciklas-Wright H et al. (2000) Maternal milk consumption predicts the trade off between milk and soft drinks in young girls' diet. J Nutr 131, 246-250.

36. Keijsers L, Branje SJ, Frijns T et al. (2010) Gender differences in keeping secrets from parents in adolescence. Dev Psychol 46, 293-298.

37. Jago R, Baranowski T \& Baranowski JC (2007) Fruit and vegetable availability: a micro environmental mediating variable? Public Health Nutr 10, 681-689.

38. Vejrup K, Lien N, Klepp KI et al. (2008) Consumption of vegetables at dinner in a cohort of Norwegian adolescents. Appetite 51, 90-96.

39. Gillman MW, Rifas-Shiman SL, Frazier AL et al. (2000) Family dinner and diet quality among older children and adolescents. Arch Fam Med 9, 235-240.
40. Andersen LF, Overby NC \& Lillegaard IT (2004) Intake of fruit and vegetables among Norwegian children and adolescents [Nor]. Tidsskr Nor Laegeforen 10, 1396-1398.

41. Johansen A, Rasmussen S \& Madsen M (2006) Health behaviour among adolescents in Denmark: influence of school class and individual risk factors. Scand J Public Health 34, 32-40.

42. Bere E, van Lenthe F, Klepp KI et al. (2008) Why do parents' education level and income affect the amount of fruits and vegetables adolescents eat? Eur J Public Health 18, 611-615.

43. Turrell G \& Kavanagh AM (2006) Socio-economic pathways to diet: modelling the association between socioeconomic position and food purchasing behaviour. Public Health Nutr 9, 375-383.

44. Darmon N \& Drewnowski A (2008) Does social class predict diet quality? Am J Clin Nutr 87, 1107-1117. 